\title{
Iterative algorithms with errors for zero points of $m$-accretive operators
}

\author{
Xiaolong Qin', Sun Young Cho² and Lin Wang ${ }^{3 *}$
}

"Correspondence:

w164mail@yahoo.com.cn

${ }^{3}$ College of Statistics and

Mathematics, Yunnan University of

Finance and Economics, Kunming, 650221, China

Full list of author information is

available at the end of the article

\begin{abstract}
In this paper, we study the convergence of paths for continuous pseudocontractions in a real Banach space. As an application, we consider the problem of finding zeros of $m$-accretive operators based on an iterative algorithm with errors. Strong convergence theorems for zeros of $m$-accretive operators are established in a real Banach space.
\end{abstract}

MSC: 47H05; 47H09; 47J25; 65J15

Keywords: accretive operator; fixed point; nonexpansive mapping; iterative algorithm; zero point

\section{Introduction and preliminaries}

Let $C$ be a nonempty closed convex subset of a real Banach space $E$ and let $E^{*}$ be the dual space of $E$. Let $\langle\cdot, \cdot\rangle$ denote the pairing between $E$ and $E^{*}$. The normalized duality mapping $J: E \rightarrow 2^{E^{*}}$ is defined by

$$
J(x)=\left\{f \in E^{*}:\langle x, f\rangle=\|x\|^{2}=\|f\|^{2}\right\}
$$

for all $x \in E$. In the sequel, we use $j$ to denote the single-valued normalized duality mapping. Let $U_{E}=\{x \in E:\|x\|=1\}$. E is said to be smooth or is said to have a Gâteaux differentiable norm if the limit

$$
\lim _{t \rightarrow 0} \frac{\|x+t y\|-\|x\|}{t}
$$

exists for each $x, y \in U_{E} . E$ is said to have a uniformly Gâteaux differentiable norm if for each $y \in U_{E}$, the limit is attained uniformly for all $x \in U_{E}$. $E$ is said to be uniformly smooth or is said to have a uniformly Fréchet differentiable norm if the limit is attained uniformly for $x, y \in U_{E}$. It is known that if the norm of $E$ is uniformly Gâteaux differentiable, then the duality mapping $J$ is single-valued and uniformly norm to weak continuous on each bounded subset of $E$.

Recall that a closed convex subset $C$ of a Banach space $E$ is said to have a normal structure if for each bounded closed convex subset $K$ of $C$ which contains at least two points, there exists an element $x$ of $K$ which is not a diametral point of $K$, i.e.,

$$
\sup \{\|x-y\|: y \in K\}<d(K)
$$

o 2013 Qin et al.; licensee Springer. This is an Open Access article distributed under the terms of the Creative Commons Attribution License (http://creativecommons.org/licenses/by/2.0), which permits unrestricted use, distribution, and reproduction in any medium, provided the original work is properly cited. 
where $d(K)$ is the diameter of $K$. It is well known that a closed convex subset of a uniformly convex Banach space has the normal structure and a compact convex subset of a Banach space has the normal structure; see [1] for more details.

Let $T: C \rightarrow C$ be a nonlinear mapping. In this paper, we use $F(T)$ to denote the set of fixed points of $T$. Recall that $T$ is said to be contractive if there exits a constant $\alpha \in(0,1)$ such that

$$
\|T x-T y\| \leq \alpha\|x-y\|, \quad \forall x, y \in C .
$$

For such a case, we also call $T$ an $\alpha$-contraction. $T$ is said to be a strong contraction if there exits a constant $\alpha \in(0,1)$ and some $j(x-y) \in J(x-y)$ such that

$$
\langle T x-T y, j(x-y)\rangle \leq \alpha\|x-y\|^{2}, \quad \forall x, y \in C .
$$

For such a case, we also call $T$ an $\alpha$-strong pseudocontraction. $T$ is said to be nonexpansive if

$$
\|T x-T y\| \leq\|x-y\|, \quad \forall x, y \in C .
$$

$T$ is said to be pseudocontractive if there exists some $j(x-y) \in J(x-y)$ such that

$$
\langle T x-T y, j(x-y)\rangle \leq\|x-y\|^{2}, \quad \forall x, y \in C .
$$

For the class of nonexpansive mappings, one classical way to study nonexpansive mappings is to use contractions to approximate a nonexpansive mapping [2,3]. More precisely, take $t \in(0,1)$ and define a contraction $T_{t}: C \rightarrow C$ by

$$
T_{t} x=t u+(1-t) T x, \quad \forall x \in C,
$$

where $u \in C$ is a fixed point. Banach's contraction mapping principle guarantees that $T_{t}$ has a unique fixed point $x_{t}$ in $C$. That is,

$$
x_{t}=t u+(1-t) T x_{t} .
$$

In the case that $T$ enjoys a fixed point, Browder [2] proved that if $E$ is a Hilbert space, then $x_{t}$ converges strongly to a fixed point of $T$. Reich [3] extended Browder's result to the setting of Banach spaces and proved that if $E$ is a uniformly smooth Banach space, then $x_{t}$ converges strongly to a fixed point of $T$.

Let $D$ be a nonempty subset of $C$. Let $Q: C \rightarrow D$. $Q$ is said to be contraction if $Q^{2}=Q$; sunny if for each $x \in C$ and $t \in(0,1)$, we have $Q(t x+(1-t) Q x)=Q x$; sunny nonexpansive retraction if $Q$ is sunny, nonexpansive, and contraction. $K$ is said to be a nonexpansive retract of $C$ if there exists a nonexpansive retraction from $C$ onto $D$.

The following result, which was established in $[4,5]$, describes a characterization of sunny nonexpansive retractions on a smooth Banach space.

Let $E$ be a smooth Banach space and let $C$ be a nonempty subset of $E$. Let $Q: E \rightarrow C$ be a retraction and let $j$ be the normalized duality mapping on $E$. Then the following are equivalent: 
(1) $Q$ is sunny and nonexpansive;

(2) $\|Q x-Q y\|^{2} \leq\langle x-y, j(Q x-Q y)\rangle, \forall x, y \in E$;

(3) $\langle x-Q x, j(y-Q x)\rangle \leq 0, \forall x \in E, y \in C$.

Recently, $\mathrm{Xu}[6]$ improved Reich's results by considering the viscosity approximation method which was first introduced by Moudafi [7]. To be more precise, he studied the following continuous scheme:

$$
x_{t}=t f\left(x_{t}\right)+(1-t) T x_{t},
$$

where $f$ is an $\alpha$-contraction and $T$ is a nonexpansive mapping. He showed that the sequence $\left\{x_{t}\right\}$ converges strongly to a point in $F(T)$ in a uniformly smooth Banach space. If one defines $Q: \Pi_{C} \rightarrow F(T)$, where $\Pi_{C}$ denotes the set of $\alpha$-contractions, by

$$
Q(f):=\lim _{t \rightarrow \infty} x_{t}
$$

then $Q(f)$ solves the following variational inequality:

$$
\langle(I-f) Q(f), j(Q(f)-p)\rangle \leq 0, \quad \forall p \in F(T) .
$$

The questions that naturally arise in connection with Xu's results are as follows.

(1) Can one extend the framework of the space from uniformly smooth Banach spaces to a more general Banach space?

(2) Can one extend the viscosity approximation method by considering strong pseudocontractions instead of contractions?

(3) Do Xu's results still hold for a larger class of nonlinear mappings?

In Section 2, we give an affirmative answer to the above questions.

Let $I$ denote the identity operator on $E$. An operator $A \subset E \times E$ with domain $D(A)=\{z \in$ $E: A z \neq \emptyset\}$ and range $R(A)=\bigcup\{A z: z \in D(A)\}$ is said to be accretive if for each $x_{i} \in D(A)$ and $y_{i} \in A x_{i}, i=1,2$, there exists $j\left(x_{1}-x_{2}\right) \in J\left(x_{1}-x_{2}\right)$ such that

$$
\left\langle y_{1}-y_{2}, j\left(x_{1}-x_{2}\right)\right\rangle \geq 0
$$

An accretive operator $A$ is said to be $m$-accretive if $R(I+r A)=E$ for all $r>0$. In a real Hilbert space, an operator $A$ is $m$-accretive if and only if $A$ is maximal monotone. In this paper, we use $A^{-1}(0)$ to denote the set of zeros of $A$. Interest in accretive operators, which is an important class of nonlinear operators, stems mainly from their firm connection with equations of evolution. It is known that many physically significant problems can be modeled by initial value problems of the form

$$
x^{\prime}(t)+A x(t)=0, \quad x(0)=x_{0},
$$

where $A$ is an accretive operator in an appropriate Banach space. Typical examples where such evolution equations occur can be found in the heat, wave or Schrödinger equations. If $x(t)$ is dependent on $t$, then (1.1) is reduced to

$$
A u=0,
$$


whose solutions correspond to the equilibrium points of the system (1.1). Consequently, considerable research efforts have been devoted, especially within the past 40 years or so, to methods for finding approximate solutions (when they exist) of equation (1.2). An early fundamental result in the theory of accretive operators, due to Browder [8], states that the initial value problem (1.1) is solvable if $A$ is locally Lipschitz and accretive on $E$.

For an accretive operator $A$, we can define a nonexpansive single-valued mapping $J_{r}$ : $R(I+r A) \rightarrow D(A)$ by $J_{r}=(I+r A)^{-1}$ for each $r>0$, which is called the resolvent of $A$.

One of classical methods for studying the problem $0 \in A x$, where $A \subset E \times E$ is an accretive operator, is the following:

$$
x_{0} \in E, \quad x_{n+1}=J_{r_{n}} x_{n}, \quad \forall n \geq 0,
$$

where $J_{r_{n}}=\left(I+r_{n} A\right)^{-1}$ and $\left\{r_{n}\right\}$ is a sequence of positive real numbers.

As we know, many well-known problems arising in various branches of science can be studied by using algorithms which are iterative in their nature. As an example, in computer tomography with limited data, each piece of information implies the existence of a convex set in which the required solution lies. The problem of finding a point in the intersection of the sets is then of crucial interest, and it cannot be usually solved directly. Therefore, an iterative algorithm must be used to approximate such a point.

Recall that the normal Mann iterative process was introduced by Mann [9] in 1953. The normal Mann iterative process generates a sequence $\left\{x_{n}\right\}$ in the following manner:

$$
\forall x_{1} \in C, \quad x_{n+1}=\left(1-\alpha_{n}\right) x_{n}+\alpha_{n} T x_{n}, \quad \forall n \geq 1,
$$

where $\left\{\alpha_{n}\right\}$ is a sequence in the interval $(0,1)$. If $T$ is a nonexpansive mapping with a fixed point and the control sequence $\left\{\alpha_{n}\right\}$ is chosen so that $\sum_{n=1}^{\infty} \alpha_{n}\left(1-\alpha_{n}\right)=\infty$, then the sequence $\left\{x_{n}\right\}$ generated in the normal Mann iterative process converges weakly to a fixed point of $T$. In an infinite-dimensional Hilbert space, the normal Mann iteration process has only weak convergence, in general, even for nonexpansive mappings. Therefore, many authors try to modify the normal Mann iterative process to have strong convergence for nonexpansive mappings; see, e.g., [10-24] and the references therein.

Recently, Qin and Su [18] studied the problem of modifying the normal Mann iterative process to have strong convergence for $m$-accretive operators. To be more precise, they considered the following iterative process:

$$
\left\{\begin{array}{l}
x_{1} \in C, \\
y_{n}=\beta_{n} x_{n}+\left(1-\beta_{n}\right) J_{r_{n}} x_{n}, \\
x_{n+1}=\alpha u+\left(1-\alpha_{n}\right) y_{n}, \quad \forall n \geq 1,
\end{array}\right.
$$

where $u$ is a fixed element in $C$ and $J_{r_{n}}=\left(I+r_{n} A\right)^{-1}$. They proved that the sequence $\left\{x_{n}\right\}$ generated in the above iterative process converges strongly to a zero of $A$.

In this paper, we study the convergence of paths for continuous pseudocontractions in a real Banach space by viscosity approximation methods. As applications, we consider the problem of finding zeros of $m$-accretive operators based on an iterative process with errors. Strong convergence theorems of zeros are established in a real Banach space.

In order to prove our main results, we also need the following lemmas. 
Lemma 1.1 [25] Let $\left\{a_{n}\right\},\left\{b_{n}\right\}$, and $\left\{c_{n}\right\}$ be three nonnegative real sequences satisfying

$$
a_{n+1} \leq\left(1-t_{n}\right) a_{n}+b_{n}+c_{n}, \quad \forall n \geq 0,
$$

where $\left\{t_{n}\right\}$ is a sequence in $(0,1)$. Assume that the following conditions are satisfied:

(a) $\sum_{n=0}^{\infty} t_{n}=\infty$ and $b_{n}=o\left(t_{n}\right)$;

(b) $\sum_{n=0}^{\infty} c_{n}<\infty$.

Then $\lim _{n \rightarrow \infty} a_{n}=0$.

Lemma 1.2 [26] Let $C$ be a nonempty, bounded, closed, and convex subset of a reflexive Banach space $E$ which also has the normal structure. Let $T$ be a nonexpansive mapping of $C$ into itself. Then $F(T)$ is nonempty.

Lemma 1.3 [27] Let C be a nonempty, closed, and convex subset of a Banach space E, and let $T: C \rightarrow C$ be a continuous and strong pseudocontraction. Then $T$ has a unique fixed point in $C$.

Lemma 1.4 [28] In a Banach space E, there holds the inequality

$$
\|x+y\|^{2} \leq\|x\|^{2}+2\langle y, j(x+y)\rangle, \quad \forall x, y \in E,
$$

where $j(x+y) \in J(x+y)$.

Set $A=(0,1)$, let $B(A)$ denote the Banach space of all bounded real-valued functions on $A$ with a supremum norm and let $X$ be a subspace of $B(A)$.

Lemma 1.5 [1] Let C be a nonempty, closed, and convex subset of a Banach space E. Suppose that the norm of $E$ is uniformly Gâteaux differentiable. Let $\left\{x_{t}\right\}$ be a bounded set in $E$, and $z \in C$. Let $\mu_{t}$ be a mean on $X$. Then $\mu_{t}\left\|x_{t}-z\right\|^{2}=\min _{y \in C}\left\|x_{t}-y\right\|$ if and only if $\mu_{t}\left\langle y-z, x_{t}-z\right\rangle \leq 0$ for all $y \in C$.

Lemma 1.6 [29] Let E be a Banach space and let $A$ be an m-accretive operator. For $\lambda>0$, $\mu>0$, and $x \in E$, we have

$$
J_{\lambda} x=J_{\mu}\left(\frac{\mu}{\lambda} x+\left(1-\frac{\mu}{\lambda}\right) J_{\lambda} x\right)
$$

where $J_{\lambda}=(I+\lambda A)^{-1}$ and $J_{\mu}=(I+\mu A)^{-1}$.

Lemma 1.7 [30] Let $\left\{x_{n}\right\}$ and $\left\{y_{n}\right\}$ be bounded sequences in a Banach space E, and let $\left\{\beta_{n}\right\}$ be a sequence in $(0,1)$ with

$$
0<\liminf _{n \rightarrow \infty} \beta_{n} \leq \limsup _{n \rightarrow \infty} \beta_{n}<1 .
$$

Suppose that $x_{n+1}=\left(1-\beta_{n}\right) y_{n}+\beta_{n} x_{n}, \forall n \geq 1$ and

$$
\limsup _{n \rightarrow \infty}\left(\left\|y_{n+1}-y_{n}\right\|-\left\|x_{n+1}-x_{n}\right\|\right) \leq 0 .
$$

Then $\lim _{n \rightarrow \infty}\left\|y_{n}-x_{n}\right\|=0$. 


\section{Main results}

Now, we are in a position to prove the strong convergence of paths for continuous pseudocontractions.

Theorem 2.1 Let E be a real reflexive Banach space with the uniformly Gâteaux differentiable norm and the normal structure, and let $C$ be a nonempty closed convex subset of $E$. Let $T: C \rightarrow C$ be a continuous pseudocontraction with a fixed point, and let $f: C \rightarrow C$ be a fixed continuous bounded and strong pseudocontraction with the coefficient $\alpha \in(0,1)$. Let $\left\{x_{t}\right\}$ be a sequence generated by the following:

$$
x_{t}=t f\left(x_{t}\right)+(1-t) T x_{t},
$$

where $t \in(0,1)$. Then $\left\{x_{t}\right\}$ converges strongly as $t \rightarrow 0$ to a fixed point $x^{*}$ of $T$, which is the unique solution in $F(T)$ to the following variational inequality:

$$
\left\langle f\left(x^{*}\right)-x^{*}, j\left(x^{*}-p\right)\right\rangle \geq 0, \quad \forall p \in F(T) .
$$

Proof For $t \in(0,1)$, define a mapping $T_{t}^{f}: C \rightarrow C$ by

$$
T_{t}^{f} x=t f(x)+(1-t) T x
$$

Then $T_{t}^{f}: C \rightarrow C$ is a continuous, strong pseudocontraction for each $t \in(0,1)$. Indeed, we have

$$
\begin{aligned}
\left\langle T_{t}^{f} x-T_{t}^{f} y, j(x-y)\right\rangle & =t\langle f(x)-f(y), j(x-y)\rangle+(1-t)\langle T x-T y, j(x-y)\rangle \\
& \leq t \alpha\|x-y\|^{2}+(1-t)\|x-y\|^{2} \\
& =(1-t(1-\alpha))\|x-y\|^{2}, \quad \forall x, y \in C .
\end{aligned}
$$

In view of Lemma 1.3, we see that $T_{t}^{f}$ has a unique fixed point $x_{t}$ in $C$ for each $t \in(0,1)$. Hence (2.1) is well defined. Next, we show that $\left\{x_{t}\right\}$ is bounded. For any $p \in F(T)$ and $t \in(0,1)$, we see that

$$
\begin{aligned}
\left\|x_{t}-p\right\|^{2} & =\left\langle x_{t}-p, j\left(x_{t}-p\right)\right\rangle \\
& =t\left\langle f\left(x_{t}\right)-p, j\left(x_{t}-p\right)\right\rangle+(1-t)\left\langle T x_{t}-p, j\left(x_{t}-p\right)\right\rangle \\
& =t\left\langle f\left(x_{t}\right)-f(p), j\left(x_{t}-p\right)\right\rangle+t\left\langle f(p)-p, j\left(x_{t}-p\right)\right\rangle+(1-t)\left\langle T x_{t}-p, j\left(x_{t}-p\right)\right\rangle \\
& \leq t \alpha\left\|x_{t}-p\right\|^{2}+t\left\langle f(p)-p, j\left(x_{t}-p\right)\right\rangle+(1-t)\left\|x_{t}-p\right\|^{2} \\
& \leq(1-t(1-\alpha))\left\|x_{t}-p\right\|^{2}+t\left\langle f(p)-p, j\left(x_{t}-p\right)\right\rangle,
\end{aligned}
$$

which implies that

$$
\left\|x_{t}-p\right\|^{2} \leq \frac{1}{1-\alpha}\left\langle f(p)-p, j\left(x_{t}-p\right)\right\rangle .
$$

It follows that

$$
\left\|x_{t}-p\right\| \leq \frac{1}{1-\alpha}\|f(p)-p\| .
$$


This shows that $\left\{x_{t}\right\}$ is bounded, so is $\left\{T x_{t}\right\}$. On the other hand, we see from (2.1) that

$$
x_{t}-T x_{t}=t\left(f\left(x_{t}\right)-T x_{t}\right) .
$$

Since $f$ and $\left\{x_{t}\right\}$ are bounded, we obtain that $f\left(x_{t}\right)$ is bounded. It follows that

$$
\lim _{t \rightarrow 0}\left\|x_{t}-T x_{t}\right\|=0
$$

Define $g(x)=\mu_{t}\left\|x_{t}-x\right\|^{2}, \forall x \in C$, where $\mu_{t}$ is a Banach limit. Then $g(x)$ is continuous, convex and $g(x) \rightarrow \infty$ as $\|x\| \rightarrow \infty$. We see that $g$ attains its infinimum over $C$ (see, e.g., [1]). Set

$$
D=\left\{x \in C: g(x)=\inf _{y \in C} g(y)\right\}
$$

Then $D$ is a nonempty bounded closed convex subset of $C$. Next, we show that there exits a point $x^{*} \in D$ such that $T x^{*}=x^{*}$.

Indeed, for any $y \in C$, define a mapping $S: C \rightarrow C$ by

$$
S x=\frac{1}{2} y+\frac{1}{2} T x, \quad \forall x \in C
$$

It is easy to see that $S$ is a continuous strong pseudocontraction. From Lemma 1.3, we see that $S$ has a unique fixed point $x$ in $C$, that is, $x=\frac{1}{2} y+\frac{1}{2} T x$. This implies that

$$
y=(2 I-T) x \in(2 I-T)(C) .
$$

This shows that $C \subseteq(2 I-T)(C)$. Define another mapping $h: C \rightarrow C$ by

$$
h(x)=(2 I-T)^{-1} x, \quad \forall x \in C .
$$

We see that $h$ is a nonexpansive mapping. Indeed, we have

$$
\begin{aligned}
\|h(x)-h(y)\| & =\left\|(2 I-T)^{-1} x-(2 I-T)^{-1} y\right\| \\
& \leq\left\|(I+(I-T))^{-1} x-(I+(I-T))^{-1} y\right\| \\
& \leq\|x-y\|, \quad \forall x, y \in C .
\end{aligned}
$$

We also see that $F(h)=F(T)$. Indeed,

$$
x=h(x) \Longleftrightarrow 2 x-T x=x \quad \Longleftrightarrow \quad x=T x .
$$

On the other hand, we have

$$
\begin{aligned}
\|x-h(x)\| & =\left\|h h^{-1}(x)-h(x)\right\| \\
& \leq\left\|h^{-1}(x)-x\right\| \\
& =\|(2 I-T)(x)-x\| \\
& =\|x-T x\| .
\end{aligned}
$$


It follows from (2.4) that

$$
\lim _{t \rightarrow 0}\left\|x_{t}-h\left(x_{t}\right)\right\|=0
$$

Fixing $x \in D$, we have

$$
\begin{aligned}
g(h(x)) & =\mu_{t}\left\|x_{t}-h(x)\right\|^{2} \\
& =\mu_{t}\left\|h\left(x_{t}\right)-h(x)\right\|^{2} \\
& \leq \mu_{t}\left\|x_{t}-x\right\|^{2} \\
& =g(x) .
\end{aligned}
$$

This implies that $h(x) \in D$, that is, $h(D) \subseteq D$. Since $C$ is a nonempty closed convex subset of $E$ which has the normal structure, we see that $h$ has a fixed point. We denote it by $x^{*}$. It follows from $F(h)=F(T)$ that $T x^{*}=x^{*}$. From Lemma 1.5, we see that

$$
\mu_{t}\left\langle p-x^{*}, j\left(x_{t}-x^{*}\right)\right| \leq 0, \quad \forall p \in C
$$

In particular, we have

$$
\mu_{t}\left\langle f\left(x^{*}\right)-x^{*}, j\left(x_{t}-x^{*}\right)\right\rangle \leq 0 \text {. }
$$

In view of (2.2), we arrive at

$$
\mu_{t}\left\|x_{t}-x^{*}\right\|^{2} \leq 0
$$

This implies that there exists a subnet $\left\{x_{t_{\alpha}}\right\}$ of $\left\{x_{t}\right\}$ such that $x_{t_{\alpha}} \rightarrow x^{*}$.

On the other hand, we have

$$
x_{t}-f\left(x_{t}\right)=(1-t)\left(T x_{t}-f\left(x_{t}\right)\right) \text {. }
$$

For any $p \in F(T)$, we see that

$$
\begin{aligned}
\left\langle x_{t}\right. & \left.-f\left(x_{t}\right), j\left(x_{t}-p\right)\right\rangle \\
= & (1-t)\left\langle T x_{t}-f\left(x_{t}\right), j\left(x_{t}-p\right)\right\rangle \\
& =(1-t)\left\langle T x_{t}-x_{t}, j\left(x_{t}-p\right)\right\rangle+(1-t)\left\langle x_{t}-f\left(x_{t}\right), j\left(x_{t}-p\right)\right\rangle \\
& =(1-t)\left\langle T x_{t}-p, j\left(x_{t}-p\right)\right\rangle+(1-t)\left\langle p-x_{t}, j\left(x_{t}-p\right)\right\rangle+(1-t)\left\langle x_{t}-f\left(x_{t}\right), j\left(x_{t}-p\right)\right\rangle \\
& \leq(1-t)\left\langle x_{t}-f\left(x_{t}\right), j\left(x_{t}-p\right)\right\rangle,
\end{aligned}
$$

which implies that

$$
\left\langle x_{t}-f\left(x_{t}\right), j\left(x_{t}-p\right)\right\rangle \leq 0, \quad \forall p \in F(T) .
$$

In particular, we have

$$
\left\langle x_{t_{\alpha}}-f\left(x_{t_{\alpha}}\right), j\left(x_{t_{\alpha}}-p\right)\right\rangle \leq 0, \quad \forall p \in F(T) .
$$


It follows that

$$
\left\langle x^{*}-f\left(x^{*}\right), j\left(x^{*}-p\right)\right\rangle \leq 0, \quad \forall p \in F(T) .
$$

If there exits another subnet $\left\{x_{t_{\beta}}\right\}$ of $\left\{x_{t}\right\}$ such that $x_{t_{\beta}} \rightarrow x^{* * *} \in F(T)$. From (2.8), we arrive at

$$
\left\langle x^{*}-f\left(x^{*}\right), j\left(x^{*}-x^{* *}\right)\right\rangle \leq 0 \text {. }
$$

It also follows from (2.6) that

$$
\left\langle x_{t_{\beta}}-f\left(x_{t_{\beta}}\right), j\left(x_{t_{\beta}}-x^{\prime \prime}\right)\right\rangle \leq 0 \text {. }
$$

It follows that

$$
\left\langle x^{* *}-f\left(x^{* *}\right), j\left(x^{* *}-x^{*}\right)\right\rangle \leq 0 .
$$

Adding up (2.9) and (2.11), we obtain that

$$
\left\langle x^{*}-f\left(x^{*}\right)-x^{* * *}+f\left(x^{* * *}\right), j\left(x^{*}-x^{* *}\right)\right\rangle \leq 0 \text {. }
$$

This implies that

$$
\left\|x^{*}-x^{* *}\right\|^{2} \leq \alpha\left\|x^{*}-x^{* * *}\right\|^{2} \text {. }
$$

Note that $\alpha \in(0,1)$. We see that $x^{*}=x^{* *}$. This shows that $\left\{x_{t}\right\}$ converges strongly to $x^{*} \in$ $F(T)$, which is the unique solution to the variational inequality

$$
\left\langle(f-I) x^{*}, p-x^{*}\right\rangle \leq 0, \quad \forall p \in F(T) .
$$

This completes the proof.

Remark 2.2 Note that uniformly smooth Banach spaces enjoy the uniformly Gâteaux differentiable norm and the uniform normal structure. Theorem 2.1, which gives an affirmative answer to the questions presented in Section 1, improves Theorem 4.1 of $\mathrm{Xu}$ [6] in the following aspects:

(1) improves the framework of spaces from uniformly smooth Banach spaces to the Banach space with the uniformly Gâteaux differentiable norm;

(2) improves the mapping $f$ from the class of contractions to the class of strongly pseudocontractions;

(3) improves the mapping $T$ from the class of nonexpansive mappings to the class of pseudocontractions.

Remark 2.3 Under the conditions of Theorem 2.1, we can define a mapping $Q: \Pi_{C} \rightarrow$ $F(T)$, where $\Pi_{C}$ denotes the set of continuous bounded and strong pseudocontractions, by

$$
Q(f):=\lim _{t \rightarrow 0} x_{t}, \quad f \in \Pi_{C} .
$$


It is not hard to see that $Q$ is a sunny nonexpansive retraction from $\Pi_{C}$ onto $F(T)$.

Remark 2.4 If $T$ is a nonexpansive mapping and $f(x)=u$, a fixed element for every $x \in C$ in Theorem 2.1, then $\left\{x_{t}\right\}$ defined by

$$
x_{t}=t u+(1-t) T x_{t},
$$

where $t \in(0,1)$, converges strongly as $t \rightarrow 0$ to a fixed point $Q(u)$ of $T$, where $Q$ is the sunny nonexpansive retraction from $C$ onto $F(T)$. The point $Q(u)$ is the unique solution in $F(T)$ to the following variational inequality:

$$
\langle u-Q(u), j(Q(u)-p)\rangle \geq 0, \quad \forall p \in F(T) .
$$

Next, we prove strong convergence of iterative processes with errors for $m$-accretive operators.

Theorem 2.5 Let E be a real reflexive Banach space with the uniformly Gâteaux differentiable norm and let $A$ be an m-accretive operator in $E$. Assume that $C:=\overline{D(A)}$ is convex and has the normal structure. Let $\left\{\alpha_{n}\right\},\left\{\beta_{n}\right\},\left\{\gamma_{n}\right\}$, and $\left\{\delta_{n}\right\}$ be real number sequences in $(0,1)$. Let $Q_{C}$ be a sunny nonexpansive retraction from $E$ onto $C$ and let $\left\{x_{n}\right\}$ be a sequence generated in the following manner:

$$
\left\{\begin{array}{l}
x_{0} \in C, \\
y_{n}=\beta_{n} x_{n}+\gamma_{n} J_{r_{n}}\left(x_{n}+e_{n+1}\right)+\delta_{n} Q_{C} f_{n}, \\
x_{n+1}=\alpha_{n} u+\left(1-\alpha_{n}\right) y_{n}, \quad \forall n \geq 0,
\end{array}\right.
$$

where $\left\{e_{n}\right\}$ is a sequence in $E,\left\{f_{n}\right\}$ is a bounded sequence in $E,\left\{r_{n}\right\}$ is a positive real numbers sequence, $u$ is a fixed element in $C$ and $J_{r_{n}}=\left(I+r_{n} A\right)^{-1}$. Assume that $A^{-1}(0) \neq \emptyset$ and the above control sequences satisfy the following restrictions:

(a) $\beta_{n}+\gamma_{n}+\delta_{n}=1$ for each $n \geq 0$;

(b) $\lim _{n \rightarrow \infty} \alpha_{n}=0$ and $\sum_{n=1}^{\infty} \alpha_{n}=\infty$;

(c) $0<\liminf _{n \rightarrow \infty} \beta_{n} \leq \limsup _{n \rightarrow \infty} \beta_{n}<1$;

(d) $\sum_{n=1}^{\infty}\left\|e_{n}\right\|<\infty$ and $\sum_{n=0}^{\infty} \delta_{n}<\infty$;

(e) $r_{n} \geq \epsilon$ for each $n \geq 1$ and $\lim _{n \rightarrow \infty}\left|r_{n}-r_{n+1}\right|=0$.

Then the sequence $\left\{x_{n}\right\}$ generated by $(\Delta)$ converges strongly to a zero $Q(u)$ of $A$, which is the unique solution to the following variational inequality:

$$
\langle(f-I) Q(u), p-Q(u)\rangle \leq 0, \quad \forall p \in A^{-1}(0) .
$$

Proof First, we prove that $\left\{x_{n}\right\}$ is bounded. Fixing $p \in A^{-1}(0)$, we see that

$$
\begin{aligned}
& \left\|x_{1}-p\right\| \\
& \quad=\left\|\alpha_{0}(u-p)+\left(1-\alpha_{0}\right)\left(y_{0}-p\right)\right\| \\
& \quad \leq \alpha_{0}\|u-p\|+\left(1-\alpha_{0}\right)\left\|y_{0}-p\right\| \\
& \quad=\alpha_{0}\|u-p\|+\left(1-\alpha_{0}\right)\left(\left\|\beta_{0}\left(x_{0}-p\right)+\gamma_{0}\left(J_{r_{0}}\left(x_{0}+e_{1}\right)-p\right)+\delta_{0}\left(Q_{C} f_{0}-p\right)\right\|\right)
\end{aligned}
$$




$$
\begin{aligned}
& \leq \alpha_{0}\|u-p\|+\left(1-\alpha_{0}\right)\left(\beta_{0}\left\|x_{0}-p\right\|+\gamma_{0}\left\|J_{r_{0}}\left(x_{0}+e_{1}\right)-p\right\|+\delta_{0}\left\|f_{0}-p\right\|\right) \\
& \leq \alpha_{0}\|u-p\|+\left(1-\alpha_{0}\right)\left(\left(1-\delta_{0}\right)\left\|x_{0}-p\right\|+\left\|e_{1}\right\|+\delta_{0}\left\|f_{0}-p\right\|\right) \\
& \leq K
\end{aligned}
$$

where $K=\|u-p\|+\left\|x_{0}-p\right\|+\left\|e_{1}\right\|+\left\|f_{0}-p\right\|<\infty$. Put

$$
M_{1}=\max \left\{K, \sup _{n \geq 0}\left\|f_{n}-p\right\|\right\}
$$

Next, we prove that

$$
\left\|x_{n}-p\right\| \leq M_{1}+\sum_{i=1}^{n}\left\|e_{i}\right\|, \quad \forall n \geq 1
$$

It is easy to see that (2.12) holds for $n=1$. We assume that the result holds for some $n$. It follows that

$$
\begin{aligned}
& \left\|x_{n+1}-p\right\| \\
& \quad \leq \alpha_{n}\|u-p\|+\left(1-\alpha_{n}\right)\left\|y_{n}-p\right\| \\
& \quad \alpha_{n}\|u-p\|+\left(1-\alpha_{n}\right)\left(\left\|\beta_{n}\left(x_{n}-p\right)+\gamma_{n}\left(J_{r_{n}}\left(x_{n}+e_{n+1}\right)-p\right)+\delta_{n}\left(Q_{C} f_{n}-p\right)\right\|\right) \\
& \leq \alpha_{n}\|u-p\|+\left(1-\alpha_{n}\right)\left(\beta_{n}\left\|x_{n}-p\right\|+\gamma_{n}\left\|J_{r_{n}}\left(x_{n}+e_{n+1}\right)-p\right\|+\delta_{n}\left\|f_{n}-p\right\|\right) \\
& \leq \alpha_{n}\|u-p\|+\left(1-\alpha_{n}\right)\left(\left(1-\delta_{n}\right)\left\|x_{n}-p\right\|+\left\|e_{n+1}\right\|+\delta_{n}\left\|f_{n}-p\right\|\right) \\
& \leq \alpha_{n} M_{1}+\left(1-\alpha_{n}\right)\left(\left(1-\delta_{n}\right)\left(M_{1}+\sum_{i=1}^{n}\left\|e_{i}\right\|\right)+\left\|e_{n+1}\right\|+\delta_{n} M_{1}\right) \\
& \quad=M_{1}+\sum_{i=1}^{n+1}\left\|e_{i}\right\| .
\end{aligned}
$$

This shows that (2.12) holds for all $n \geq 1$. If $r_{n+1} \geq r_{n}$, we see from Lemma 1.6 that

$$
\begin{aligned}
& \left\|J_{r_{n}}\left(x_{n}+e_{n+1}\right)-J_{r_{n+1}}\left(x_{n+1}+e_{n+2}\right)\right\| \\
& \quad \leq\left\|\frac{r_{n}}{r_{n+1}}\left(x_{n}+e_{n+1}\right)+\left(1-\frac{r_{n}}{r_{n+1}}\right) J_{r_{n+1}}\left(x_{n}+e_{n+1}\right)-\left(x_{n+1}+e_{n+2}\right)\right\| \\
& \quad=\left\|\frac{r_{n}}{r_{n+1}}\left(\left(x_{n}+e_{n+1}\right)-\left(x_{n+1}+e_{n+2}\right)\right)+\frac{r_{n+1}-r_{n}}{r_{n+1}}\left(J_{r_{n+1}}\left(x_{n}+e_{n+1}\right)-\left(x_{n+1}+e_{n+2}\right)\right)\right\| \\
& \quad \leq\left\|x_{n}-x_{n+1}\right\|+\left\|e_{n+1}\right\|+\left\|e_{n+2}\right\|+\frac{M_{2}}{\epsilon}\left(r_{n+1}-r_{n}\right),
\end{aligned}
$$

where $M_{2}$ is an appropriate constant such that

$$
M_{2} \geq \sup _{n \geq 1}\left\{\left\|J_{r_{n+1}}\left(x_{n}+e_{n+1}\right)-\left(x_{n+1}+e_{n+2}\right)\right\|\right\} .
$$

Put $g_{n}=\frac{x_{n+1}-\beta_{n} x_{n}}{1-\beta_{n}}$. This implies that

$$
x_{n+1}=\left(1-\beta_{n}\right) g_{n}+\beta_{n} x_{n}, \quad n \geq 0 \text {. }
$$


Now, we compute $\left\|g_{n+1}-g_{n}\right\|$. Note that

$$
\begin{aligned}
g_{n+1}-g_{n}= & \frac{\alpha_{n+1} u+\left(1-\alpha_{n+1}\right) y_{n+1}-\beta_{n+1} x_{n+1}}{1-\beta_{n+1}}-\frac{\alpha_{n} u+\left(1-\alpha_{n}\right) y_{n}-\beta_{n} x_{n}}{1-\beta_{n}} \\
= & \frac{\alpha_{n+1}\left(u-y_{n+1}\right)+\gamma_{n+1} J_{r_{n+1}}\left(x_{n+1}+e_{n+2}\right)+\delta_{n+1} Q_{C} f_{n+1}}{1-\beta_{n+1}} \\
& -\frac{\alpha_{n}\left(u-y_{n}\right)+\gamma_{n} J_{r_{n}}\left(x_{n}+e_{n+1}\right)+\delta_{n} Q_{C} f_{n}}{1-\beta_{n}} \\
= & \frac{\alpha_{n+1}\left(u-y_{n+1}\right)+\delta_{n+1}\left(Q_{C} f_{n+1}-J_{r_{n+1}}\left(x_{n+1}+e_{n+2}\right)\right)}{1-\beta_{n+1}} \\
& -\frac{\alpha_{n}\left(u-y_{n}\right)+\delta_{n}\left(Q_{C} f_{n}-J_{r_{n}}\left(x_{n}+e_{n+1}\right)\right)}{1-\beta_{n}} \\
& +J_{r_{n+1}}\left(x_{n+1}+e_{n+2}\right)-J_{r_{n}}\left(x_{n}+e_{n+1}\right) .
\end{aligned}
$$

It follows that

$$
\begin{aligned}
& \left\|g_{n+1}-g_{n}\right\| \\
& \leq \frac{\alpha_{n+1}}{1-\beta_{n+1}}\left\|u-y_{n+1}\right\|+\frac{\alpha_{n}}{1-\beta_{n}}\left\|y_{n}-u\right\| \\
& \quad+\left\|\frac{\delta_{n+1}}{1-\beta_{n+1}}\left(Q_{C} f_{n+1}-J_{r_{n+1}}\left(x_{n+1}+e_{n+2}\right)\right)-\frac{\delta_{n}}{1-\beta_{n}}\left(Q_{C} f_{n}-J_{r_{n}}\left(x_{n}+e_{n+1}\right)\right)\right\| \\
& \quad+\left\|J_{r_{n+1}}\left(x_{n+1}+e_{n+2}\right)-J_{r_{n}}\left(x_{n}+e_{n+1}\right)\right\| \\
& \leq \frac{\alpha_{n+1}}{1-\beta_{n+1}}\left\|u-y_{n+1}\right\|+\frac{\alpha_{n}}{1-\beta_{n}}\left\|y_{n}-u\right\|+\frac{\delta_{n+1}}{1-\beta_{n+1}}\left\|Q_{C} f_{n+1}-J_{r_{n+1}}\left(x_{n+1}+e_{n+2}\right)\right\| \\
& \quad+\frac{\delta_{n}}{1-\beta_{n}}\left\|Q_{C} f_{n}-J_{r_{n}}\left(x_{n}+e_{n+1}\right)\right\|+\left\|J_{r_{n+1}}\left(x_{n+1}+e_{n+2}\right)-J_{r_{n}}\left(x_{n}+e_{n+1}\right)\right\| .
\end{aligned}
$$

Substituting (2.13) into (2.16), we arrive at

$$
\begin{aligned}
& \left\|g_{n+1}-g_{n}\right\|-\left\|x_{n}-x_{n+1}\right\| \\
& \leq \frac{\alpha_{n+1}}{1-\beta_{n+1}}\left\|u-y_{n+1}\right\|+\frac{\alpha_{n}}{1-\beta_{n}}\left\|y_{n}-u\right\|+\left\|e_{n+1}\right\|+\left\|e_{n+2}\right\| \\
& \quad+\frac{M_{2}}{\epsilon}\left|r_{n+1}-r_{n}\right|+\frac{\alpha_{n}}{1-\beta_{n}}\left\|y_{n}-u\right\|+\frac{\delta_{n+1}}{1-\beta_{n+1}}\left\|Q_{C} f_{n+1}-J_{r_{n+1}}\left(x_{n+1}+e_{n+2}\right)\right\| \\
& \quad+\frac{\delta_{n}}{1-\beta_{n}}\left\|Q_{C} f_{n}-J_{r_{n}}\left(x_{n}+e_{n+1}\right)\right\| .
\end{aligned}
$$

In a similar way, we can obtain (2.17) when $r_{n} \geq r_{n+1}$. From the conditions (b)-(e), we see that

$$
\limsup _{n \rightarrow \infty}\left(\left\|g_{n+1}-g_{n}\right\|-\left\|x_{n}-x_{n+1}\right\|\right) \leq 0
$$

It follows from Lemma 1.7 that

$$
\lim _{n \rightarrow \infty}\left\|g_{n}-x_{n}\right\|=0 .
$$


In view of (2.14), we have

$$
x_{n+1}-x_{n}=\left(1-\beta_{n}\right)\left(g_{n}-x_{n}\right) \text {, }
$$

which combines with the condition (c) and (2.18) gives that

$$
\lim _{n \rightarrow \infty}\left\|x_{n+1}-x_{n}\right\|=0
$$

On the other hand, we see from the algorithm $(\Delta)$ that

$$
\begin{aligned}
& \left\|x_{n}-J_{r_{n}}\left(x_{n}+e_{n+1}\right)\right\| \\
& \quad \leq\left\|x_{n}-x_{n+1}\right\|+\left\|x_{n+1}-y_{n}\right\|+\left\|y_{n}-J_{r_{n}}\left(x_{n}+e_{n+1}\right)\right\| \\
& \quad \leq\left\|x_{n}-x_{n+1}\right\|+\alpha_{n}\left\|u-y_{n}\right\|+\beta_{n}\left\|x_{n}-J_{r_{n}}\left(x_{n}+e_{n+1}\right)\right\|+\delta_{n}\left\|Q_{C} f_{n}-x_{n}\right\| .
\end{aligned}
$$

This implies that

$$
\left(1-\beta_{n}\right)\left\|x_{n}-J_{r_{n}}\left(x_{n}+e_{n+1}\right)\right\| \leq\left\|x_{n}-x_{n+1}\right\|+\alpha_{n}\left\|u-y_{n}\right\|+\delta_{n}\left\|Q_{C} f_{n}-x_{n}\right\| .
$$

From the conditions (b)-(d) and (2.19), we conclude that

$$
\lim _{n \rightarrow \infty}\left\|x_{n}-J_{r_{n}}\left(x_{n}+e_{n+1}\right)\right\|=0
$$

Since $\sum_{n=1}^{\infty}\left\|e_{n}\right\|<\infty$, we see that

$$
\lim _{n \rightarrow \infty}\left\|x_{n}-J_{r_{n}} x_{n}\right\|=0
$$

Take a fixed number $r$ such that $\epsilon>r>0$. From Lemma 1.6, we obtain that

$$
\begin{aligned}
\left\|J_{r_{n}} x_{n}-J_{r} x_{n}\right\| & =\left\|J_{r}\left(\frac{r}{r_{n}} x_{n}+\left(1-\frac{r}{r_{n}}\right) J_{r_{n}} x_{n}\right)-J_{r} x_{n}\right\| \\
& \leq\left\|\left(1-\frac{r}{r_{n}}\right)\left(J_{r_{n}} x_{n}-x_{n}\right)\right\| \\
& \leq\left\|J_{r_{n}} x_{n}-x_{n}\right\| .
\end{aligned}
$$

Note that

$$
\begin{aligned}
\left\|x_{n}-J_{r} x_{n}\right\| & =\left\|x_{n}-J_{r_{n}} x_{n}+J_{r_{n}} x_{n}-J_{r} x_{n}\right\| \\
& \leq\left\|x_{n}-J_{r_{n}} x_{n}\right\|+\left\|J_{r_{n}} x_{n}-J_{r} x_{n}\right\| \\
& \leq 2\left\|x_{n}-J_{r_{n}} x_{n}\right\| .
\end{aligned}
$$

From (2.21), we see that

$$
\lim _{n \rightarrow \infty}\left\|x_{n}-J_{r} x_{n}\right\|=0
$$


Next, we claim that

$$
\limsup _{n \rightarrow \infty}\left\langle u-Q(u), j\left(x_{n}-Q(u)\right)\right\rangle \leq 0,
$$

where

$$
Q u=\lim _{t \rightarrow 0} z_{t}, \quad u \in C
$$

and $z_{t}$ solves the fixed point equation

$$
z_{t}=t u+(1-t) J_{r} z_{t}, \quad \forall t \in(0,1),
$$

from which it follows that

$$
\left\|z_{t}-x_{n}\right\|=\left\|(1-t)\left(J_{r} z_{t}-x_{n}\right)+t\left(u-x_{n}\right)\right\| .
$$

For any $t \in(0,1)$, we see that

$$
\begin{aligned}
\left\|z_{t}-x_{n}\right\|^{2}= & (1-t)\left\langle J_{r} z_{t}-x_{n}, j\left(z_{t}-x_{n}\right)\right\rangle+t\left\langle u-x_{n}, j\left(z_{t}-x_{n}\right)\right\rangle \\
= & (1-t)\left(\left\langle J_{r} z_{t}-J_{r} x_{n}, j\left(z_{t}-x_{n}\right)\right\rangle+\left\langle J_{r} x_{n}-x_{n}, j\left(z_{t}-x_{n}\right)\right\rangle\right) \\
& +t\left\langle u-z_{t}, j\left(z_{t}-x_{n}\right)\right\rangle+t\left\langle z_{t}-x_{n}, j\left(z_{t}-x_{n}\right)\right\rangle \\
\leq & (1-t)\left(\left\|z_{t}-x_{n}\right\|^{2}+\left\|J_{r} x_{n}-x_{n}\right\|\left\|z_{t}-x_{n}\right\|\right) \\
& +t\left\langle u-z_{t}, j\left(z_{t}-x_{n}\right)\right\rangle+t\left\|z_{t}-x_{n}\right\|^{2} \\
\leq & \left\|z_{t}-x_{n}\right\|^{2}+\left\|J_{r} x_{n}-x_{n}\right\|\left\|z_{t}-x_{n}\right\|+t\left\langle u-z_{t}, j\left(z_{t}-x_{n}\right)\right\rangle .
\end{aligned}
$$

It follows that

$$
\left\langle z_{t}-u, j\left(z_{t}-x_{n}\right)\right\rangle \leq \frac{1}{t}\left\|J_{r} x_{n}-x_{n}\right\|\left\|z_{t}-x_{n}\right\|, \quad \forall t \in(0,1) .
$$

In view of (2.23), we see that

$$
\limsup _{n \rightarrow \infty}\left\langle z_{t}-u, j\left(z_{t}-x_{n}\right)\right\rangle \leq 0
$$

Since $z_{t} \rightarrow Q(u)$ as $t \rightarrow 0$ and the fact that $j$ is strong to weak ${ }^{*}$ uniformly continuous on bounded subsets of $E$, we see that

$$
\begin{aligned}
& \left|\left\langle u-Q(u), j\left(x_{n}-Q(u)\right)\right\rangle-\left\langle z_{t}-u, j\left(z_{t}-x_{n}\right)\right\rangle\right| \\
& \leq\left|\left\langle u-Q(u), j\left(x_{n}-Q(u)\right)\right\rangle-\left\langle u-Q(u), j\left(x_{n}-z_{t}\right)\right\rangle\right| \\
& \quad+\left|\left\langle u-Q(u), j\left(x_{n}-z_{t}\right)\right\rangle-\left\langle z_{t}-u, j\left(z_{t}-x_{n}\right)\right\rangle\right| \\
& \leq\left|\left\langle u-Q(u), j\left(x_{n}-Q(u)\right)-j\left(x_{n}-z_{t}\right)\right\rangle\right|+\left|\left\langle z_{t}-Q(u), J\left(x_{n}-z_{t}\right)\right\rangle\right| \\
& \leq\|u-Q(u)\|\left\|j\left(x_{n}-Q(u)\right)-j\left(x_{n}-z_{t}\right)\right\|+\left\|z_{t}-Q(u)\right\|\left\|x_{n}-z_{t}\right\| \rightarrow 0 \quad \text { as } t \rightarrow 0 .
\end{aligned}
$$


Hence, for any $\epsilon>0$, there exists $\delta>0$ such that $\forall t \in(0, \delta)$ the following inequality holds:

$$
\left\langle u-Q(u), j\left(x_{n}-Q(u)\right)\right\rangle \leq\left\langle z_{t}-u, j\left(z_{t}-x_{n}\right)\right\rangle+\epsilon .
$$

This implies that

$$
\underset{n \rightarrow \infty}{\limsup }\left\langle u-Q(u), j\left(x_{n}-Q(u)\right)\right\rangle \leq \limsup _{n \rightarrow \infty}\left\langle z_{t}-u, j\left(z_{t}-x_{n}\right)\right\rangle+\epsilon
$$

Since $\epsilon$ is arbitrary and (2.25), we see that $\lim _{\sup } \operatorname{su}_{n \rightarrow \infty}\left\langle u-Q(u), j\left(x_{n}-Q(u)\right)\right\rangle \leq 0$. That is,

$$
\limsup _{n \rightarrow \infty}\left\langle u-Q(u), j\left(x_{n+1}-Q(u)\right)\right\rangle \leq 0
$$

Finally, we show that $x_{n} \rightarrow Q(u)$ as $n \rightarrow \infty$. Note that

$$
\begin{aligned}
\left\|y_{n}-Q(u)\right\| & =\left\|\beta_{n} x_{n}+\gamma_{n} J_{r_{n}}\left(x_{n}+e_{n+1}\right)+\delta_{n} Q_{C} f_{n}-Q(u)\right\| \\
& \leq \beta_{n}\left\|x_{n}-Q(u)\right\|+\gamma_{n}\left\|J_{r_{n}}\left(x_{n}+e_{n+1}\right)-Q(u)\right\|+\delta_{n}\left\|Q_{C} f_{n}-Q(u)\right\| \\
& \leq\left(\beta_{n}+\gamma_{n}\right)\left\|x_{n}-Q(u)\right\|+\left\|e_{n+1}\right\|+\delta_{n}\left\|f_{n}-Q(u)\right\| \\
& \leq\left\|x_{n}-Q(u)\right\|+\eta_{n},
\end{aligned}
$$

where $\eta_{n}=\left\|e_{n+1}\right\|+\delta_{n} M_{1}$. From the condition (d), we see that $\sum_{n=0}^{\infty} \eta_{n}<\infty$. It follows from Lemma 1.5 that

$$
\begin{aligned}
&\left\|x_{n+1}-Q(u)\right\|^{2} \\
&=\left\|\left(1-\alpha_{n}\right)\left(y_{n}-Q(u)\right)+\alpha_{n}(u-Q(u))\right\|^{2} \\
& \leq\left(1-\alpha_{n}\right)^{2}\left\|y_{n}-Q(u)\right\|^{2}+2 \alpha_{n}\left\langle u-Q(u), J\left(x_{n+1}-Q(u)\right)\right\rangle \\
& \leq\left(1-\alpha_{n}\right)\left(\left\|x_{n}-Q(u)\right\|+\eta_{n}\right)^{2}+2 \alpha_{n}\left\langle u-Q(u), J\left(x_{n+1}-Q(u)\right)\right\rangle \\
&=\left(1-\alpha_{n}\right)\left(\left\|x_{n}-Q(u)\right\|^{2}+2 \eta_{n}\left\|x_{n}-Q(u)\right\|+\eta_{n}^{2}\right) \\
&+2 \alpha_{n}\left\langle u-Q(u), J\left(x_{n+1}-Q(u)\right)\right\rangle \\
&\left(1-\alpha_{n}\right)\left\|x_{n}-Q(u)\right\|^{2}+\eta_{n} M_{3}+2 \alpha_{n}\left\langle u-Q(u), J\left(x_{n+1}-Q(u)\right)\right\rangle,
\end{aligned}
$$

where $M_{3}$ is an appropriate constant such that $M_{3} \geq \sup _{n \geq 0}\left\{2\left\|x_{n}-Q(u)\right\|+\eta_{n}\right\}$. Let $\lambda_{n+1}=$ $\max \left\{\left\langle u-Q(u), J\left(x_{n+1}-Q(u)\right)\right\rangle, 0\right\}$. Next, we show that $\lim _{n \rightarrow \infty} \lambda_{n+1}=0$. Indeed, from (2.26), for any given $\epsilon>0$, there exists a positive integer $n_{1}$ such that

$$
\left\langle u-Q(u), J\left(x_{n+1}-Q(u)\right)\right\rangle<\epsilon, \quad \forall n \geq n_{1} .
$$

This implies that $0 \leq \lambda_{n+1}<\epsilon, \forall n \geq n_{1}$. Since $\epsilon>0$ is arbitrary, we see that $\lim _{n \rightarrow \infty} \lambda_{n+1}=0$. It follows from (2.27) that

$$
\left\|x_{n+1}-Q(u)\right\|^{2} \leq\left(1-\alpha_{n}\right)\left\|x_{n}-Q(u)\right\|^{2}+\eta_{n} M_{3}+2 \alpha_{n} \lambda_{n+1} .
$$


Put $a_{n}=\left\|x_{n}-Q(u)\right\|^{2}, t_{n}=\alpha_{n}, b_{n}=2 \alpha_{n} \lambda_{n+1}$ and $c_{n}=\eta_{n} M_{3}$ for every $n \geq 0$. In view of Lemma 1.1, we can obtain the desired conclusion easily.

As an application of Theorem 2.5, we have the following results.

Corollary 2.6 Let E be a real reflexive Banach space with the uniformly Gâteaux differentiable norm and let $A$ be an m-accretive operator in $E$. Assume that $C:=\overline{D(A)}$ is convex and has the normal structure. Let $\left\{\alpha_{n}\right\}$ and $\left\{\beta_{n}\right\}$ be real number sequences in $(0,1)$. Let $\left\{x_{n}\right\}$ be a sequence generated by $(Q S)$, where $\left\{r_{n}\right\}$ is a positive real numbers sequence, $u$ is a fixed element in $C$ and $J_{r_{n}}=\left(I+r_{n} A\right)^{-1}$. Assume that $A^{-1}(0) \neq \emptyset$ and the above control sequences satisfy the following restrictions:

(a) $\lim _{n \rightarrow \infty} \alpha_{n}=0$ and $\sum_{n=1}^{\infty} \alpha_{n}=\infty$;

(b) $0<\liminf _{n \rightarrow \infty} \beta_{n} \leq \limsup _{n \rightarrow \infty} \beta_{n}<1$;

(c) $r_{n} \geq \epsilon$ for each $n \geq 1$ and $\lim _{n \rightarrow \infty}\left|r_{n}-r_{n+1}\right|=0$.

Then the sequence $\left\{x_{n}\right\}$ converges strongly to a zero of $A$.

Remark 2.7 Corollary 2.6 improves Theorem 2.1 of Qin and Su [18]. To be more precise, we partially relax the restrictions on the parameters and extend the framework of the space; see [18] for more details.

Remark 2.8 It is of interest to design an explicit iterative process to approximate zeros of accretive operators by Moudafi's viscosity approximation method with continuous strong pseudocontractions.

\section{Competing interests}

The authors declare that they have no competing interests.

\section{Authors' contributions}

All authors contributed equally and significantly in writing this paper. All authors read and approved the final manuscript.

\section{Author details}

${ }^{1}$ Department of Mathematics, Hangzhou Normal University, Hangzhou, 310036, China. ${ }^{2}$ Department of Mathematics, Gyeongsang National University, Jinju, 660-701, Korea. ${ }^{3}$ College of Statistics and Mathematics, Yunnan University of Finance and Economics, Kunming, 650221, China.

Received: 20 March 2013 Accepted: 21 May 2013 Published: 6 June 2013

References

1. Takahashi, W: Nonlinear Functional Analysis - Fixed Point Theory and Its Application. Yokohama Publishers, Yokohama (2000)

2. Browder, FE: Convergence of approximants to fixed points of nonexpansive nonlinear mappings in Banach spaces. Arch. Ration. Mech. Anal. 24, 82-90 (1967)

3. Reich, S: Strong convergence theorems for resolvents of accretive operators in Banach spaces. J. Math. Anal. Appl. 75, 287-292 (1980)

4. Bruck, RE: Nonexpansive projections on subsets of Banach spaces. Pac. J. Math. 47, 341-355 (1973)

5. Reich, S: Asymptotic behavior of contractions in Banach spaces. J. Math. Anal. Appl. 44, 57-70 (1973)

6. Xu, HK: Viscosity approximation methods for nonexpansive mappings. J. Math. Anal. Appl. 298, $279-291$ (2004)

7. Moudafi, A: Viscosity approximation methods for fixed-points problems. J. Math. Anal. Appl. 241, $46-55$ (2000)

8. Browder, FE: Nonlinear mappings of nonexpansive and accretive type in Banach spaces. Bull. Am. Math. Soc. 73, 875-882 (1967)

9. Mann, WR: Mean value methods in iteration. Proc. Am. Math. Soc. 4, 506-510 (1953)

10. Ceng, LC, Khan, AR, Ansari, QH, Yao, JC: Strong convergence of composite iterative schemes for zeros of $m$-accretive operators in Banach spaces. Nonlinear Anal. 70, 1830-1840 (2009)

11. Ye, J, Huang, J: Strong convergence theorems for fixed point problems and generalized equilibrium problems of three relatively quasi-nonexpansive mappings in Banach spaces. J. Math. Comput. Sci. 1, 1-18 (2011)

12. Zegeye, $\mathrm{H}$, Shahzad, N: Strong convergence theorem for a common point of solution of variational inequality and fixed point problem. Adv. Fixed Point Theory 2, 374-397 (2012) 
13. Song, Y, Chen, R: An approximation method for continuous pseudocontractive mappings. J. Inequal. Appl. 2006, Article ID 28950 (2006)

14. Luo, $\mathrm{H}$, Wang, Y: Iterative approximation for the common solutions of a infinite variational inequality system for inverse-strongly accretive mappings. J. Math. Comput. Sci. 2, 1660-1670 (2012)

15. Chen, R, Lin, PK, Song, Y: An approximation method for strictly pseudocontractive mappings. Nonlinear Anal. 64, 2527-2535 (2006)

16. Qing, Y, Kim, JK: Weak convergence of algorithms for asymptotically strict pseudocontractions in the intermediate sense and equilibrium problems. Fixed Point Theory Appl. 2012, 132 (2012)

17. Kim, JK: Strong convergence theorems by hybrid projection methods for equilibrium problems and fixed point problems of the asymptotically quasi- $\phi$-nonexpansive mappings. Fixed Point Theory Appl. 2011, 10 (2011)

18. Qin, X, Su, Y: Approximation of a zero point of accretive operator in Banach spaces. J. Math. Anal. Appl. 329, 415-424 (2007)

19. Wang, Z, Lou, W: A new iterative algorithm of common solutions to quasi-variational inclusion and fixed point problems. J. Math. Comput. Sci. 3, 57-72 (2013)

20. Cho, SY, Kang, SM: Approximation of fixed points of pseudocontraction semigroups based on a viscosity iterative process. Appl. Math. Lett. 24, 224-228 (2011)

21. Marino, G, Colao, V, Qin, X, Kang, SM: Strong convergence of the modified Mann iterative method for strict pseudo-contractions. Comput. Math. Appl. 57, 455-465 (2009)

22. Cho, YJ, Kang, SM, Qin, X: Approximation of common fixed points of an infinite family of nonexpansive mappings in Banach spaces. Comput. Math. Appl. 56, 2058-2064 (2008)

23. Jung, JS: Convergence of composite iterative methods for finding zeros of accretive operators. Nonlinear Anal. 71 1736-1746 (2009)

24. Qin, X, Cho, SY, Kang, SM: Strong convergence of shrinking projection methods for quasi- $\phi$-nonexpansive mappings and equilibrium problems. J. Comput. Appl. Math. 234, 750-760 (2010)

25. Liu, LS: Ishikawa and Mann iterative processes with errors for nonlinear strongly accretive mappings in Banach spaces. J. Math. Anal. Appl. 194, 114-125 (1995)

26. Kirk, WA: A fixed point theorem for mappings which do not increase distances. Am. Math. Mon. 72, 1004-1006 (1965)

27. Deimling, K: Zeros of accretive operators. Manuscr. Math. 13, 365-374 (1974)

28. Jung, JS, Cho, YJ, Zhou, H: Iterative processes with mixed errors for nonlinear equations with perturbed $m$-accretive operators in Banach spaces. Appl. Math. Comput. 133, 389-406 (2002)

29. Barbu, V: Nonlinear Semigroups and Differential Equations in Banach Space. Noordhoff, Leiden (1976)

30. Suzuki, T: Strong convergence of Krasnoselskii and Mann's type sequences for one-parameter nonexpansive semigroups without Bochne integrals. J. Math. Anal. Appl. 305, 227-239 (2005)

\section{Submit your manuscript to a SpringerOpen ${ }^{\circ}$ journal and benefit from:}

- Convenient online submission

Rigorous peer review

- Immediate publication on acceptance

- Open access: articles freely available online

- High visibility within the field

- Retaining the copyright to your article 